\title{
PEMILIHAN UNIVERSITAS FAVORIT DENGAN PENDEKATAN RANTAI MARKOV
}

\author{
Tinjung Desy Nursanti ${ }^{1}$; Laksmi Sito Dwi Irianti ${ }^{2}$ Haryadi Sarjono $^{3}$ \\ 1,2,3 Jurusan Manajemen, Fakultas Ekonomi dan Bisnis, Universitas Bina Nusantara, \\ Jln. K.H. Syahdan No. 9, Palmerah, Jakarta Barat 11480 \\ tinjungdesy@yahoo.com
}

\begin{abstract}
The purpose of this study was to determine the amount of transfer of interest at class XII students in a private high school in Bogor to five universities in the Greater Jakarta namely UI, UBinus, Untar, IPB and UPH in the next period and the conditions of equilibrium, and to discover the source of reference selection and assessment of students on the fifth university. Sample consists of 411 class XII students in a private high school in Bogor, with the method and type of survey research is descriptive research. The result is a prediction of the five university in order in the next period of $(0.22,0.31,0.14,0.22,0.11)$ when the equilibrium prediction of $(0.15,0.562,0.076,0.151,0.09)$ and the selection of a reference source that is $29 \%$ of promotional events, $25 \%$ of the ads, $24 \%$ of the families, and $22 \%$ from friends. Largest market share held by UBinus enthusiasts of $56.2 \%$, while the smallest market share owned by Untar enthusiasts that is equal to $7.6 \%$.
\end{abstract}

Keywords: Markov Chain, favorite, SMA, Bogor, university

\begin{abstract}
ABSTRAK
Tujuan penelitian ini adalah untuk mengetahui besarnya perpindahan, peminatan pelajar kelas XII SMA Swasta di Bogor terhadap lima universitas di Jabodetabek, yaitu UI, UBinus, Untar, IPB, dan UPH pada periode berikutnya, dan kondisi ekuilibrium serta untuk mengetahui sumber referensi pemilihan dan penilaian pelajar terhadap kelima universitas tersebut. Sampelnya terdiri dari 411 pelajar kelas XII SMA Swasta Bogor, dengan metode penelitian adalah survei dan jenis penelitiannya deskriptif. Hasilnya adalah prediksi peminatan kelima universitas secara berurutan pada periode berikutnya sebesar $(0.22,0.31,0.14,0.22,0.11)$ prediksi saat ekuilibrium sebesar $(0.15,0.562,0.076,0.151,0.09)$ dan sumber referensi pemilihan, yaitu $29 \%$ dari event promosi, 25\% dari iklan, 24\% dari keluarga, dan 22\% dari teman. Pangsa pasar terbesar dimiliki oleh peminat UBinus sebesar 56,2\%, sedangkan pangsa pasar terkecil dimiliki oleh peminat Untar, yaitu sebesar 7.6\%.
\end{abstract}

Kata kunci: Markov Chain, favorit, SMA, Bogor, universitas 


\section{PENDAHULUAN}

Pendidikan merupakan suatu hal yang sangat penting dan mutlak bagi umat manusia suatu bangsa dan negara. Karena pendidikan adalah suatu rangkaian proses dalam rangka menghasilkan warga negara yang memiliki pengetahuan, ketrampilan, maupun watak, dan menghasilkan warga negara yang berkarakter, berperilaku lebih baik dan berbudaya, antara lain dengan memiliki kematangan emosional dan kepekaan sosial. Pendidikan tidaklah hanya sekedar transfer ilmu pengetahuan (transfer of knowledge), akan tetapi tujuan pendidikan sesungguhnya adalah untuk menciptakan pribadi yang memiliki sikap dan kepribadian yang positif (diakses April 5, 2009, dari http://www.bpplsp-reg-1.go.id/buletin/read.php?id=24\&dir=1\&idStatus $=0$ ). Perguruan Tinggi yang akan melahirkan para sarjana pun saat ini tidak kalah tumbuh pesat, tercatat ratusan perguruan tinggi ada di Indonesia yang menawarkan beragam program studi dan fasilitas yang menjanjikan. Tidak hanya itu, lembaga-lembaga kursus yang setara dengan Perguruan Tinggi pun tumbuh bak jamur di musim hujan sebagai imbas akan kebutuhan pendidikan tinggi (diakses tanggal April 5, 2009, dari http://ivanmancini.multiply.com/journal/item/22/Fenomena_Sarjana_dan_Dunia_Kerja,)

Kaum pelajar menengah atas merupakan salah satu target pasar yang memiliki potensi besar dalam memberikan profit bagi universitas. Karenanya, kini berbagai strategi pemasaran dan promosi yang gencar dilakukan oleh universitas baik melalui iklan melalui media elektronik dan cetak, dan lainnya, terutama pemasaran langsung ke sekolah-sekolah, dalam menghadapi persaingan ini dengan universitas kompetitornya (diakses tanggal April 5, 2009, dari http://www.blogtoplist.com/marketingseo/blogdetails10565-7.html). Analisis pasar ini sangat penting bagi universitas dalam meningkatkan keberhasilan bisnis-nya. Oleh sebab itu, analisis pasar berupa pemilihan universitas di kalangan pelajar SMA sebagai target utama pemasaran universitas sangat diperlukan. Tujuannya untuk mengetahui penilaian pangsa pasar para pelajar SMA terhadap universitas favorit tersebut. Mengingat banyaknya pilihan universitas dan program studi yang ditawarkan di pasar serta sering berubahnya selera konsumen, maka tidak jarang dalam kurun waktu singkat seorang pelajar dapat berpindah atau berganti pilihan universitas dari suatu universitas ke universitas lainnya. Perpindahan pelajar dalam memilih universitas yang paling disenangi selama kurun waktu tertentu akan menambah kerumitan dalam pengukuran, di mana teknik Rantai Markov (Markov Chains) dapat digunakan untuk menganalisis penilaian pangsa pasar dan perpindahan merek ataupun brand switching tersebut.

Perpindahan pelajar dalam memilih universitas yang paling disenangi selama kurun waktu tertentu akan menambah kerumitan dalam pengukuran. Dalam menghadapi permasalahan ini, maka diperlukan analisis pangsa pasar terhadap berbagai universitas favorit tersebut. Tehnik Rantai Markov (Markov Chains) dapat digunakan untuk menganalisis pendugaan pangsa pasar dan perpindahan pilihan tersebut. Siswa SMA Swasta mana yang ingin mereka memasuki dengan berbagai pertimbangan yang ada. Berdasarkan uraian tersebut, maka penulis merumuskan beberapa masalah yang akan dibahas sebagai berikut (1) Bagaimana pelajar Siswa SMA swasta di Bogor dalam memilih universitas yang menjadi favorit mereka, (2) Bagaimana 5 universitas yang ada tersebut akan dipilih oleh Siswa SMA swasta di Bogor pada kondisi ekuilibrium, (3) Dari mana siswa SMA swasta di Bogor tersebut memperoleh referensi dalam memilih universitas favorit mereka, dan (4) Bagaimana penilaian Siswa SMA Swasta di Bogor terhadap kelima Universitas yang ada.

Untuk menganalisis pasar suatu produk, beberapa alat analisisnya adalah peramalan pangsa pasar, potensi pangsa pasar (market share), dan potensi pasar (Husein Umar 2003:219). Pangsa pasar (market share) dapat diartikan sebagai bagian pasar yang dikuasai oleh suatu perusahaan, atau persentasi penjualan suatu perusahaan terhadap total penjualan para pesaing terbesarnya pada waktu dan tempat tertentu (Ismulyana dan Ramlan 2006). Menurut Ismulyana dan Ramlan (2006:4), dalam penelitiannya menyatakan bahwa besarnya pangsa pasar setiap saat akan berubah sesuai dengan perubahan selera konsumen, atau berpindahnya minat konsumen dari suatu produk ke produk lain. Salah satu teknik untuk memprediksi pangsa pasar di waktu yang akan datang adalah analisis Rantai Markov (Markov Chain). 
Pengertian teori Analisis Markov adalah sebagai berikut. Andrei Andreevich Markov (2 Juni 1856 - 20 Juli 1922) adalah seorang fisikawan Rusia. Dalam usahanya untuk menjelaskan secara matematik gejala alam yang dikenal dengan gerak Brown (Brownian motion), ia menemukan sebuah fakta yang kemudian dikenal sebagai Rantai Markov (Markov Chain). Temuan A.A. Markov adalah:

"Untuk setiap waktu t, ketika kejadian adalah $\mathrm{K}_{\mathrm{t}}$, dan seluruh kejadian sebelumnya adalah $\mathrm{K}_{\mathrm{t}}, \ldots, \mathrm{K}_{\mathrm{t}}(\mathrm{j}$-n) yang terjadi dari proses yang diketahui, probabilitas seluruh kejadian yang akan datang $\mathrm{K}_{\mathrm{t}(\mathrm{j})}$ hanya bergantung kepada kejadian $\mathrm{K}_{\mathrm{t}(\mathrm{j}-1)}$ dan tidak bergantung kepada kejadian-kejadian sebelumnya, yaitu $\mathrm{K}_{\mathrm{t}}$ $(\mathrm{j}-2), \mathrm{K}_{\mathrm{t}(\mathrm{j}-3)}, \ldots, \mathrm{K}_{\mathrm{t}(\mathrm{j}-\mathrm{n})}$."

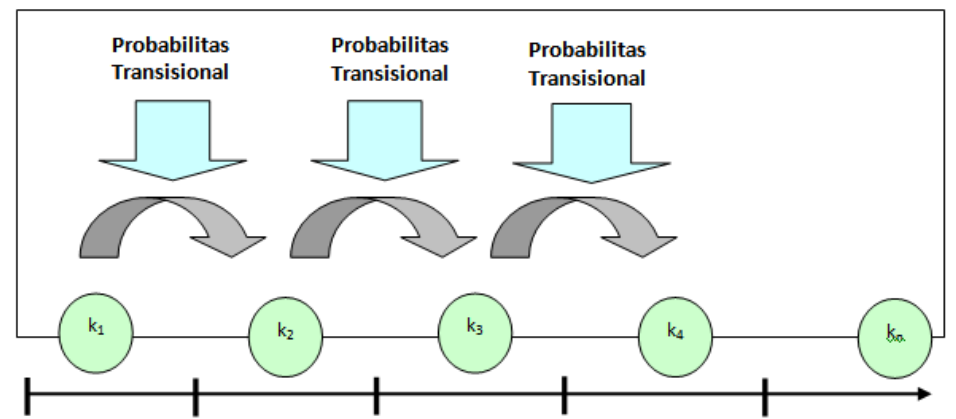

(Sumber: Siswanto, 2007)

Gambar 1 Proses Markov

Analisis Markov merupakan sebuah metode dalam menganalisis perilaku saat ini dari beberapa variable, dengan tujuan untuk memprediksi perilaku dari variabel yang sama di masa mendatang (Levin et al, 1992:802). Karena sifatnya yang berantai tersebut, maka teori ini dikenal pula dengan nama Rantai Markov. Dengan demikian, Rantai Markov akan menjelaskan gerakan-gerakan beberapa variabel dalam satu periode waktu di masa yang akan datang berdasarkan pada gerakangerakan variabel tersebut di masa kini. Secara matematik dapat ditulis sebagai berikut (Siswanto, 2007):

$$
K_{t(j)}=P \times K_{t(j-1)}
$$

dimana,

$\mathrm{K}_{\mathrm{t}(\mathrm{j})} \quad=$ Peluang Kejadian pada $\mathrm{t}_{\mathrm{j})}$

$\mathrm{P} \quad=$ Probabilitas Transisional

$\mathrm{t}_{(\mathrm{j})} \quad=$ Waktu ke-j.

Peluang kejadian $\mathrm{K}_{\mathrm{t}(\mathrm{j})}$ dalam formulasi dinyatakan ke dalam bentuk vector sehingga jumlah seluruh selnya akan selalu 100\% (Siswanto 2007:253).

Pengertian state adalah sebagai berikut. State digunakan untuk mengidentifikasi seluruh kondisi yang mungkin dari suatu proses atau sistem (Render et al, 2006:652). Misalnya saja, pelajar kelas XII di SMA Swasta Budi Mulia dan BPK Penabur Bogor dapat memilih satu di antara universitas favorit yang diminati, yaitu UI, UBinus, Untar, IPB, dan UPH. Masing-masing peminatan ini dapat dianggap sebagai sebuah state. Menurut Render et al (2006:656), salah satu tujuan analisis Markov adalah untuk memprediksi masa depan. 
Pada masa-masa awal, kehilangan maupun memperoleh pelanggan merupakan hal yang lazim terjadi. Namun, lama-kelamaan kehilangan dan perolehan pelanggan akan menjadi semakin kecil. Merupakan sebuah kondisi yang sangat masuk akal jika di masa mendatang akan tercapai suatu kondisi yang stabil, di mana semua state yang ada tidak mengalami perubahan lagi atau disebut juga dengan kondisi ekuilibrium. QM for Windows merupakan sebuah paket software untuk teknik kuantitatif yang dikembangkan oleh Professor Howard Weiss. Fitur yang disediakan QM for Windows memberikan kemudahan bagi penggunanya (Render et al, 2006:712). Untuk kerangka pemikiran dapat dilihat pada Gambar 2.

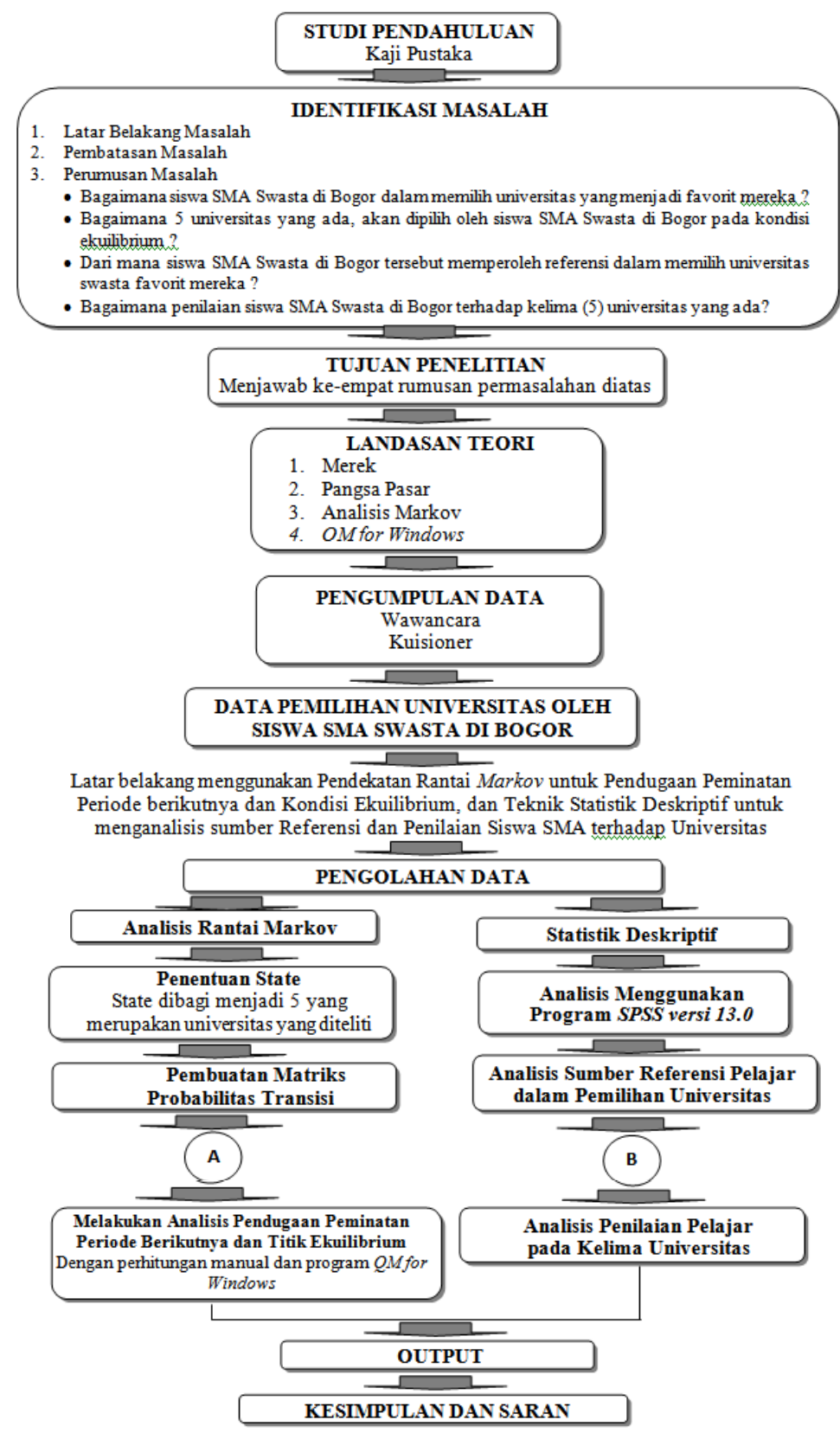

Gambar 2 Kerangka Pemikiran 


\section{METODE PENELITIAN}

\section{Gambaran Umum Subjek dan Objek Penelitian}

Subjek penelitian adalah dari mana data mengenai variabel penelitian diperoleh, dalam penelitian ini dilakukan penelitian terhadap Siswa kelas XII SMA Swasta di Bogor, dengan subjek yang berlokasi (1) SMA Swasta BUDI MULIA (218 siswa sebagai sampel penelitian) di Jalan Kapten Muslihat No. 20, Bogor; dan (2) SMA Swasta BPK PENABUR (193 siswa sebagai sampel peneltian) di Jalan Bogor Baru Blok B II, Bogor 16152.

Tabel 1 Operasional Variabel

\begin{tabular}{|c|c|c|c|}
\hline $\begin{array}{c}\text { Variabel / Sub } \\
\text { Variabel }\end{array}$ & $\begin{array}{c}\text { Konsep Variabel / Sub } \\
\text { Variabel }\end{array}$ & Indikator & $\begin{array}{c}\text { Skala } \\
\text { Pengukuran }\end{array}$ \\
\hline $\begin{array}{l}\text { Penilaian universitas } \\
\text { oleh pelajar dalam dua } \\
\text { periode. }\end{array}$ & $\begin{array}{l}\text { Pemilihan satu universitas } \\
\text { dibandingkan dengan } \\
\text { seluruh universitas tersebut. }\end{array}$ & $\begin{array}{l}\text { - Universitas yang } \\
\text { diminati pada periode } \\
\text { pertama. } \\
\text { - Universitas yang } \\
\text { diminati pada periode } \\
\text { kedua. }\end{array}$ & Nominal \\
\hline $\begin{array}{l}\text { Referensi pelajar } \\
\text { dalam pemilihan } \\
\text { universitas. }\end{array}$ & $\begin{array}{l}\text { Referensi yang diperoleh } \\
\text { pelajar dalam memilih } \\
\text { universitas. }\end{array}$ & $\begin{array}{l}\text { - Sumber referensi } \\
\text { pelajar. }\end{array}$ & Nominal \\
\hline $\begin{array}{l}\text { Penilaian pelajar } \\
\text { terhadap universitas } \\
\text { yang ada. }\end{array}$ & $\begin{array}{l}\text { Penilaian yang diberikan } \\
\text { oleh pelajar atas pemilihan } \\
\text { universitas yang ada. }\end{array}$ & $\begin{aligned} & \text { Alasan : } \\
& \text { - } \text { Fasilitas } \\
& \text { - } \text { Lokasi } \\
& \text { - } \text { Biaya Kuliah } \\
& \text { - } \text { Kualitas Pendidikan } \\
& \text { - } \text { Promosi } \\
& \text { - } \text { Brand Image } \\
& \text { - } \text { Referensi } \\
& \text { - } \text { Cita-cita } \\
&\end{aligned}$ & Interval \\
\hline
\end{tabular}

(Sumber: Hasil Pengolahan Penulis, 2009)

\section{Metode Pengumpulan Data}

Tabel 2 Desain Penelitian

\begin{tabular}{|c|c|c|c|c|}
\hline $\begin{array}{c}\text { Tujuan } \\
\text { Penelitian }\end{array}$ & $\begin{array}{c}\text { Jenis } \\
\text { Penelitian }\end{array}$ & $\begin{array}{c}\text { Metode } \\
\text { Penelitian }\end{array}$ & Unit Analisis & Horizon Waktu \\
\hline$(\mathrm{T}-1)$ & Deskriptif & Survei & Individu $\rightarrow$ Siswa SMA di Bogor & Longitudinal \\
\hline$(\mathrm{T}-2)$ & Deskriptif & Survei & Siswa SMA di Bogor & Longitudinal \\
\hline$(\mathrm{T}-3)$ & Deskriptif & Survei & Siswa SMA di Bogor & $\begin{array}{c}\text { One Shoot - Cross } \\
\text { Section }\end{array}$ \\
\hline$(\mathrm{T}-4)$ & Deskriptif & Survei & Siswa SMA di Bogor & $\begin{array}{c}\text { One Shoot - Cross } \\
\text { Section }\end{array}$ \\
\hline
\end{tabular}

(Sumber: Hasil Pengolahan Penulis, 2009) 


\section{Teknik Pengumpulan Data}

Penelitian ini menggunakan data primer dan data sekunder. Data primer ini didapatkan secara langsung dari sumber asli, yaitu data yang didapatkan dari pelajar kelas XII SMA Swasta di Bogor. Jenis data penelitian yang digunakan bersifat kuantitatif dan kualitatif, sedangkan data sekunder berupa sejarah, struktur organisasi, visi, dan misi dari lembaga pendidikan SMA Swasta tersebut.

Tabel 3 Data dan Sumber Data Penelitian

\begin{tabular}{|c|c|c|c|}
\hline $\begin{array}{l}\text { Tujuan } \\
\text { Penelitian }\end{array}$ & Data Penelitian & $\begin{array}{l}\text { Jenis Data } \\
\text { Penelitian }\end{array}$ & Sumber data penelitian \\
\hline$(\mathrm{T}-1)$ & $\begin{array}{l}\text { Penilaian pelajar terhadap } \\
\text { universitas swasta yang dipilih. }\end{array}$ & Kuantitatif & $\begin{array}{l}\text { Data primer dari kuisioner Siswa } \\
\text { SMA di Bogor }\end{array}$ \\
\hline$(\mathrm{T}-2)$ & Penilaian universitas & Kuantitatif & $\begin{array}{l}\text { Data primer dari kuisioner Siswa } \\
\text { SMA di Bogor }\end{array}$ \\
\hline$(\mathrm{T}-3)$ & $\begin{array}{l}\text { Sumber referensi pemilihan } \\
\text { universitas. }\end{array}$ & Kualitatif & $\begin{array}{l}\text { Data primer dari kuisioner Siswa } \\
\text { SMA di Bogor }\end{array}$ \\
\hline$(\mathrm{T}-4)$ & Penilaian universitas. & Kualitatif & $\begin{array}{l}\text { Data primer dari kuisioner Siswa } \\
\text { SMA di Bogor }\end{array}$ \\
\hline
\end{tabular}

(Sumber: Hasil Pengolahan Penulis, 2009)

Teknik pengumpulan data yang digunakan dalam penelitian ini adalah metode penelitian lapangan (field research) dan metode penelitian kepustakaan (library research).

\section{Metode Analisis}

Metode analisis data yang digunakan dalam penelitian ini adalah (1) Uji validitas dan reliabilitas, (2) Analisis Markov. Menjawab rumusan masalah pertama (T-1) dan kedua (T-2), yaitu mengenai pendugaan peminatan pada periode berikutnya dan pendugaan peminatan pada titik ekuilibrium; dan (3) Analisis statistik deskriptif. Menjawab rumusan masalah ketiga (T-3) dan keempat (T-4), yaitu mengenai sumber referensi pelajar dalam pemilihan universitas dan penilaian pelajar terhadap universitas yang dipilih. Analisis statistik deskriptif dilakukan dengan menggunakan paket program SPSS versi 13.0.

Tabel 4 Metode Analisis

\begin{tabular}{cccc}
\hline $\begin{array}{c}\text { Tujuan } \\
\text { Penelitian }\end{array}$ & Jenis Penelitian & $\begin{array}{c}\text { Metode } \\
\text { Penelitian }\end{array}$ & $\begin{array}{c}\text { Metode } \\
\text { Analisis }\end{array}$ \\
\hline ( T-1 $)$ & Deskriptif & Survei & Markov Analysis \\
( T-2 $)$ & Deskriptif & Survei & Markov Analysis \\
( T-3 $)$ & Deskriptif & Survei & Statistik Deskriptif \\
( T-4 $)$ & Deskriptif & Survei & Statistik Deskriptif \\
\hline
\end{tabular}

(Sumber: Hasil Pengolahan Penulis, 2009) 
HASIL DAN PEMBAHASAN

\section{Data Pemilih Universitas}

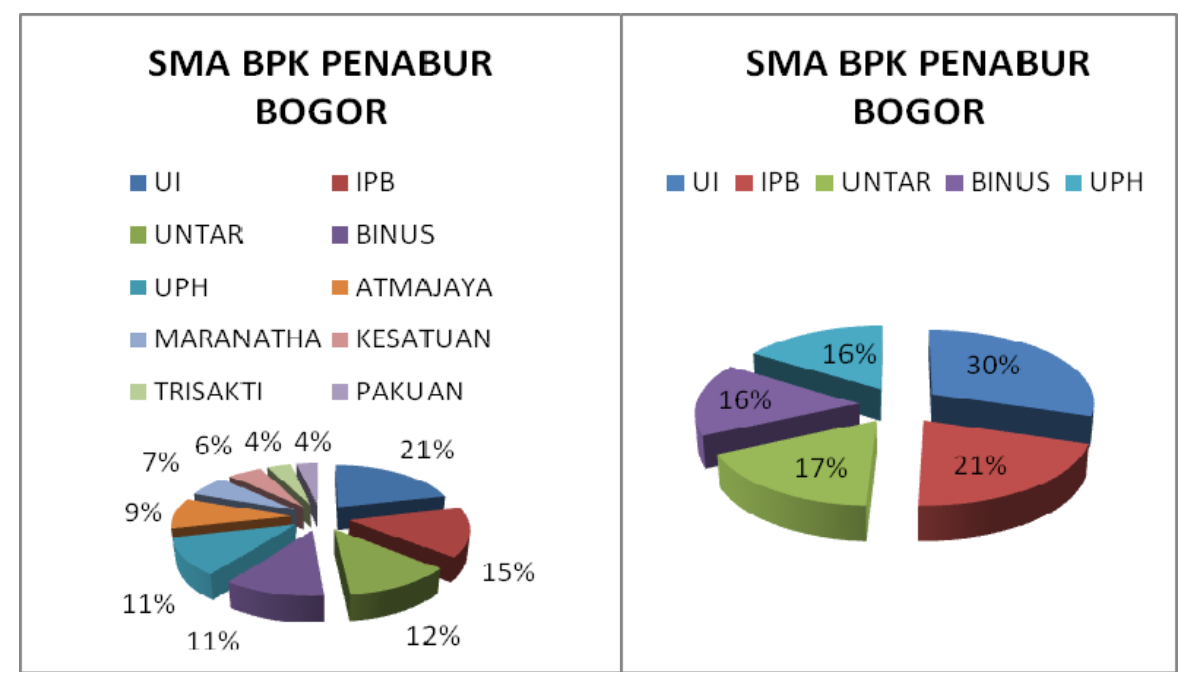

Gambar 3 Jumlah Pemilih, Probabilitas dan Proporsi pada Berbagai Universitas (KUESIONER 1)

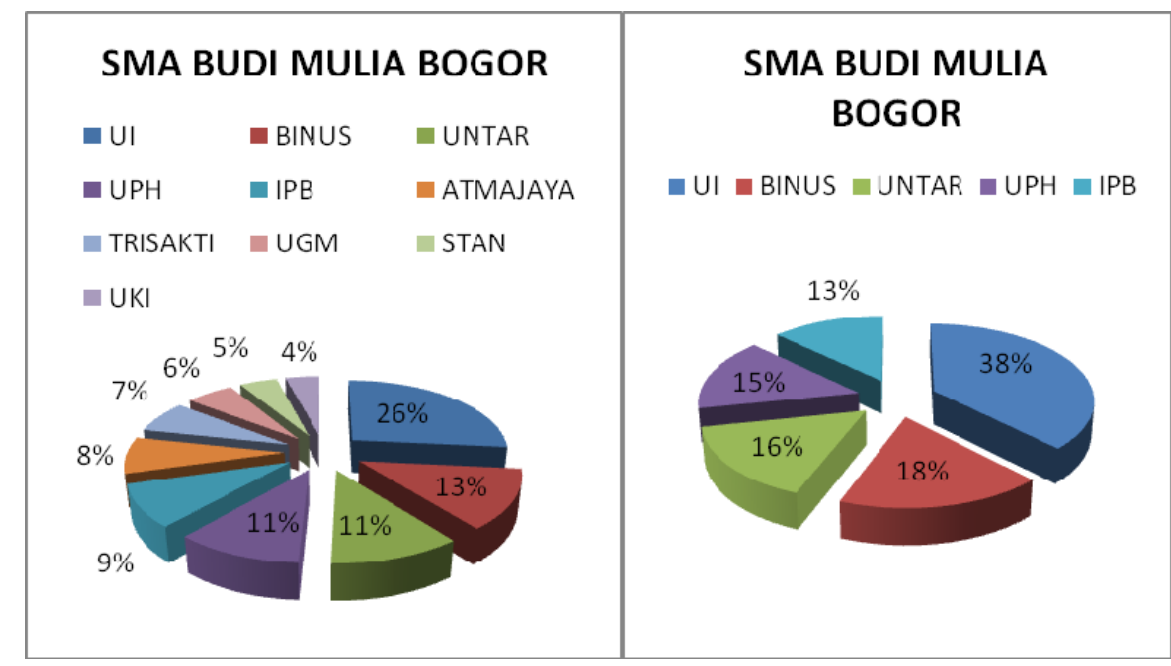

Gambar 4 Jumlah Pemilih, Probabilitas dan Proporsi pada Berbagai Universitas (KUESIONER 1)

Universitas yang diteliti yaitu UI, IPB, Untar, UBinus, UPH. Berdasarkan kuisioner pada periode kedua yang terkumpul, diperoleh data bahwa universitas-universitas yang dipilih oleh responden, dan probabilitas dari satu orang yang memilih satu diantara kelima universitas serta proporsinya. 
Tabel 5 Jumlah Pemilih, Probabilitas dan Proporsi pada Berbagai Universitas pada SMA BPK PENABUR Bogor

\begin{tabular}{|c|c|c|c|c|c|}
\hline No & Nama Universitas & State & $\begin{array}{c}\text { Jumlah } \\
\text { Responden }\end{array}$ & Probabilitas & $\begin{array}{c}\text { Proporsi } \\
(\%)\end{array}$ \\
\hline 1 & Universitas Indonesia & State 1 & 56 & 0.30 & 30 \\
\hline 2 & Institut Pertanian Bogor & State 2 & 45 & 0.23 & 23 \\
\hline 3 & Universitas Pelita Harapan & State 3 & 20 & 0.10 & 10 \\
\hline 4 & Universitas Bina Nusantara & State 4 & 35 & 0.18 & 18 \\
\hline 5 & Universitas Taruma Negara & State 5 & 37 & 0.19 & 19 \\
\hline \multicolumn{3}{|c|}{ Total } & 193 & 1.00 & 100 \\
\hline
\end{tabular}

(Sumber: Hasil Pengolahan Data, 2009)

State 1 - Universitas Indonesia

State 2 - Institut Pertanian Bogor

State 3 - Universitas Pelita Harapan

State 4 - Universitas Bina Nusantara

State 5 - Universitas Taruma Negara

$$
\begin{aligned}
& 56 / 193=0.30=\mathbf{3 0} \% \\
& 45 / 193=0.23=\mathbf{2 3 \%} \\
& 20 / 193=0.10=\mathbf{1 0} \% \\
& 35 / 193=0.18=\mathbf{1 8 \%} \\
& 37 / 193=0.19=\mathbf{1 9 \%}
\end{aligned}
$$

Tabel 6 Jumlah Pemilih, Probabilitas dan Proporsi pada Berbagai Universitas pada SMA BUDI MULIA, BOGOR

\begin{tabular}{clcccc}
\hline No & Nama Universitas & State & $\begin{array}{c}\text { Jumlah } \\
\text { Responden }\end{array}$ & Probabilitas & $\begin{array}{c}\text { Proporsi } \\
(\mathbf{\%})\end{array}$ \\
\hline 1 & Universitas Indonesia & State 1 & 35 & 0.16 & 16 \\
2 & Univ. Bina Nusantara & State 2 & 91 & 0.42 & 42 \\
3 & Univ. Taruma Negara & State 3 & 20 & 0.09 & 9 \\
4 & Universitas Pelita Harapan & State 4 & 27 & 0.12 & 12 \\
5 & Institut Pertanian Bogor & State 5 & 45 & 0.21 & 21 \\
\hline \multicolumn{2}{c}{ Total } & $\mathbf{2 1 8}$ & $\mathbf{1 , 0 0}$ & $\mathbf{1 0 0}$ \\
\hline
\end{tabular}

(Sumber: Hasil Pengolahan Data, 2009)

Tabel 7 Jumlah Pemilih, Probabilitas dan Proporsi pada Kedua SMA Swasta BOGOR

\begin{tabular}{clcccc}
\hline No & Nama Universitas & State & $\begin{array}{c}\text { Jumlah } \\
\text { Responden }\end{array}$ & Probabilitas & $\begin{array}{c}\text { Proporsi } \\
(\mathbf{\%})\end{array}$ \\
\hline 1 & Universitas Indonesia & State 1 & 91 & 0.22 & 22 \\
2 & Univ. Bina Nusantara & State 2 & 126 & 0.31 & 31 \\
3 & Univ. Taruma Negara & State 3 & 57 & 0.14 & 14 \\
4 & Institut Pertanian Bogor & State 4 & 90 & 0.22 & 22 \\
5 & Univ. Pelita Harapan & State 5 & 47 & 0.11 & 11 \\
\hline & Total & $\mathbf{4 1 1}$ & $\mathbf{1 . 0 0}$ & $\mathbf{1 0 0}$ \\
\hline
\end{tabular}

(Sumber: Hasil Pengolahan Data, 2009)

State 1 - Universitas Indonesia

State 2 - Universitas Bina Nusantara

State 3 - Universitas Taruma Negara

State 4 - Institut Pertanian Bogor

State 5 - Universitas Pelita Harapan
$91 / 411=0.22=\mathbf{2 2} \%$
$126 / 411=0.31=31 \%$
$57 / 411=0.14=14 \%$
$90 / 411=0.22=22 \%$
$47 / 411=0.11=\mathbf{1 1 \%}$ 


$$
\pi(1)=(0.22,0.31,0.14,0.22,0.11)
$$

dimana,

$\pi(1)=$ vektor probabilitas state kelima universitas untuk periode 1

$\pi_{1}=0.22=$ probabilitas satu orang yang memilih UI, state 1

$\pi_{2}=0.31=$ probabilitas satu orang yang memilih UBinus, state 2

$\pi_{3}=0.14=$ probabilitas satu orang yang memilih Untar, state 3

$\pi_{4}=0.22=$ probabilitas satu orang yang memilih IPB, state 4

$\pi_{5}=0.11=$ probabilitas satu orang yang memilih UPH, state 5

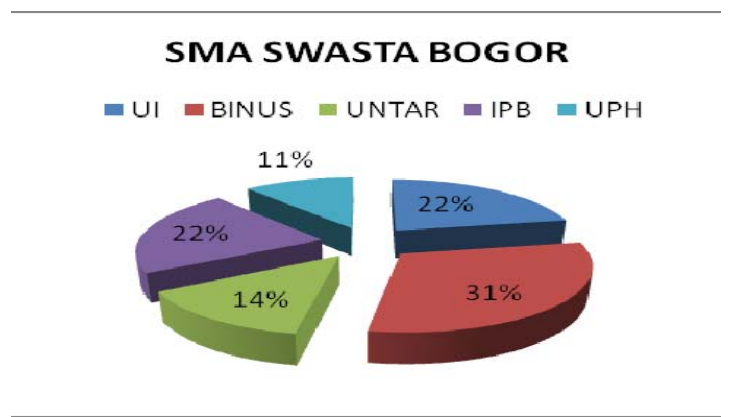

(Sumber: Hasil Pengolahan Data, 2009)

Gambar 5 Hasil Kuesioner Responden Periode 1

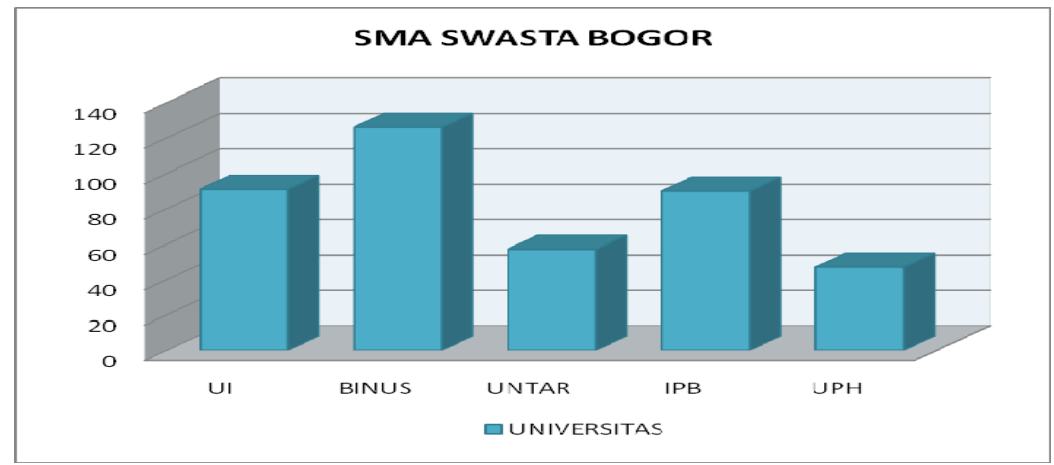

Gambar 6 Diagram Jumlah Pemilih Kelima Universitas pada Periode 2

Berdasarkan kuisioner periode ketiga, diperoleh jumlah responden yang memilih universitasuniversitas tersebut adalah seperti berikut:

Tabel 8 Jumlah Responden dan Proporsi pada Berbagai Universitas pada Kedua SMA Swasta di Bogor

\begin{tabular}{clcc}
\hline No & Nama Universitas & $\begin{array}{c}\text { Jumlah } \\
\text { Responden }\end{array}$ & Proporsi ( \% ) \\
\hline 1 & Universitas Indonesia & 76 & 18 \\
2 & Universitas Bina Nusantara & 123 & 30 \\
3 & Universitas Taruma Negara & 69 & 17 \\
4 & Institut Pertanian Bogor & 85 & 21 \\
5 & Universitas Pelita Harapan & 58 & 14 \\
\hline \multicolumn{2}{c}{ Total } & $\mathbf{4 1 1}$ & $\mathbf{1 0 0}$ \\
\hline
\end{tabular}

(Sumber: Hasil Pengolahan Data, 2009) 
Berikut ini adalah diagram yang menunjukkan jumlah responden yang memilih kelima universitas tersebut pada saat ini:

\section{SMA SWASTA BOGOR}

UI $=$ BINUS $=$ UNTAR aIPB
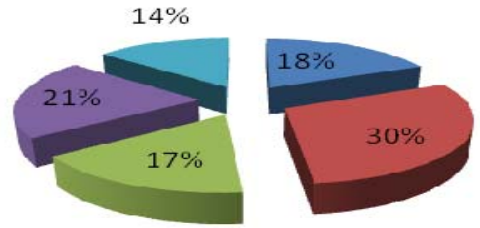

(Sumber: Hasil Pengolahan Data, 2009)

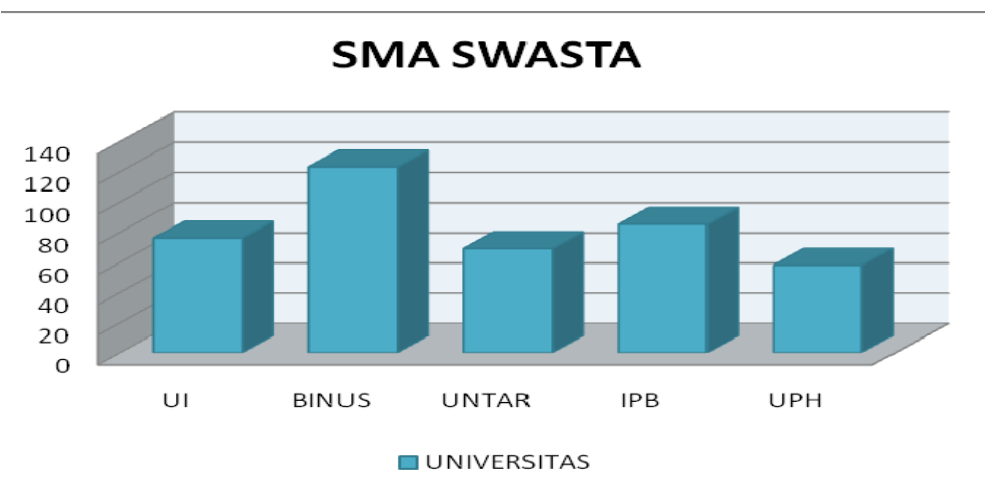

Gambar 7 Diagram Jumlah Pemilih pada Kelima Universitas Saat Ini

Penelitian pada periode kedua menunjukkan adanya perpindahan dari universitas yang satu ke universitas yang lain. Perpindahan merek adalah gejala yang umum terjadi di kalangan konsumen.

Tabel 9 Jumlah Pemilih Universitas Sebelumnya dan Saat Ini

\begin{tabular}{clcccc}
\hline No & Nama Universitas & $\begin{array}{c}\text { Jumlah } \\
\text { Universitas } \\
\text { Sebelumnya }\end{array}$ & Perolehan & Kehilangan & $\begin{array}{c}\text { Jumlah } \\
\text { Universitas } \\
\text { Saat ini }\end{array}$ \\
\hline 1 & Universitas Indonesia & 91 & 2 & 17 & 76 \\
2 & Univ. Bina Nusantara & 126 & 4 & 7 & 123 \\
3 & Univ. Taruma Negara & 57 & 21 & 9 & 69 \\
4 & Institut Pertanian Bogor & 90 & 14 & 19 & 85 \\
5 & Univ. Pelita Harapan & 47 & 18 & 7 & 58 \\
\hline \multicolumn{2}{r}{ Total } & $\mathbf{4 1 1}$ & $\mathbf{5 9}$ & $\mathbf{5 9}$ & $\mathbf{4 1 1}$ \\
\hline
\end{tabular}

(Sumber: Hasil Pengolahan Data, 2009)

Secara lebih rinci perolehan dan kehilangan konsumen pada setiap universitas yang dipilih dapat dilihat pada Tabel 14 di bawah ini. 
Tabel 10 Perolehan dan Kehilangan Konsumen pada Berbagai Universitas

\begin{tabular}{|c|c|c|c|c|c|c|c|c|c|c|}
\hline \multirow[b]{2}{*}{ 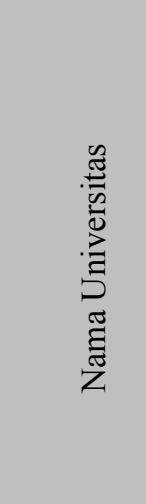 } & \multicolumn{5}{|c|}{ Perolehan } & \multicolumn{5}{|c|}{ Kehilangan } \\
\hline & 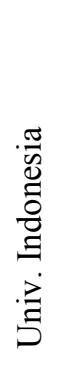 & 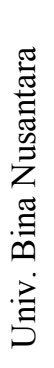 & 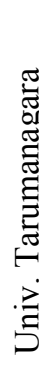 & 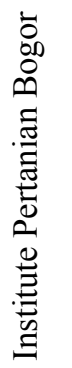 & 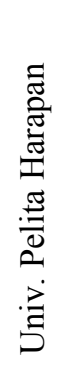 & 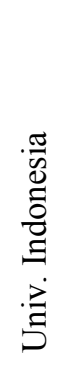 & 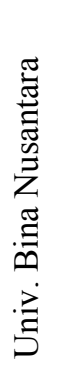 & 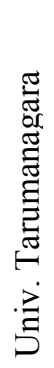 & 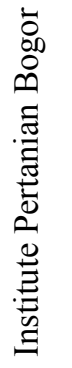 & 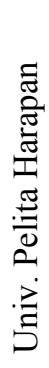 \\
\hline UI & - & 2 & 8 & 3 & 4 & - & 1 & 0 & 1 & 0 \\
\hline UBinus & 1 & - & 0 & 4 & 2 & 2 & - & 0 & 2 & 0 \\
\hline Untar & 0 & 0 & - & 5 & 4 & 8 & 0 & - & 8 & 5 \\
\hline IPB & 1 & 2 & 8 & - & 8 & 3 & 4 & 5 & - & 2 \\
\hline UPH & 0 & 0 & 5 & 2 & - & 4 & 2 & 4 & 8 & - \\
\hline \multirow{2}{*}{ Jumlah } & 2 & 4 & 21 & 14 & 18 & 17 & 7 & 9 & 19 & 7 \\
\hline & \multicolumn{5}{|c|}{ Kehilangan } & \multicolumn{5}{|c|}{ Perolehan } \\
\hline
\end{tabular}

(Sumber: Hasil Pengolahan Data, 2009)

Apabila diasumsikan bahwa pergeseran di antara merek universitas dianggap stabil, maka dapat dibuat probabilitas transisinya seperti pada Tabel 11 di bawah ini. Angka probabiltas transisi pada masing-masing universitas akan digunakan untuk mendapatkan matriks transisi probabilitas-nya.

Tabel 11 Probabilitas Transisi $(P)$

\begin{tabular}{|c|c|c|c|c|c|c|}
\hline \multirow{2}{*}{ No } & \multirow{2}{*}{ Dari } & \multicolumn{5}{|c|}{$\mathrm{Ke}$} \\
\hline & & $\mathbf{U} \mathbf{I}$ & BINUS & UNTAR & IPB & UPH \\
\hline 1 & Univ. Indonesia & 0.72 & 0.08 & 0.11 & 0.09 & 0.00 \\
\hline 2 & Univ. Bina Nusantara & 0.02 & 0.88 & 0.00 & 0.03 & 0.07 \\
\hline 3 & Univ. Taruma Negara & 0.11 & 0.12 & 0.61 & 0.05 & 0.11 \\
\hline 4 & Institut Pertanian Bogor & 0.00 & 0.22 & 0.09 & 0.65 & 0.04 \\
\hline 5 & Univ. Pelita Harapan & 0.08 & 0.14 & 0.00 & 0.21 & 0.57 \\
\hline & Market Share & 0.22 & 0.31 & 0.14 & 0.22 & 0.11 \\
\hline
\end{tabular}

(Sumber: Hasil Pengolahan Data, 2009) 


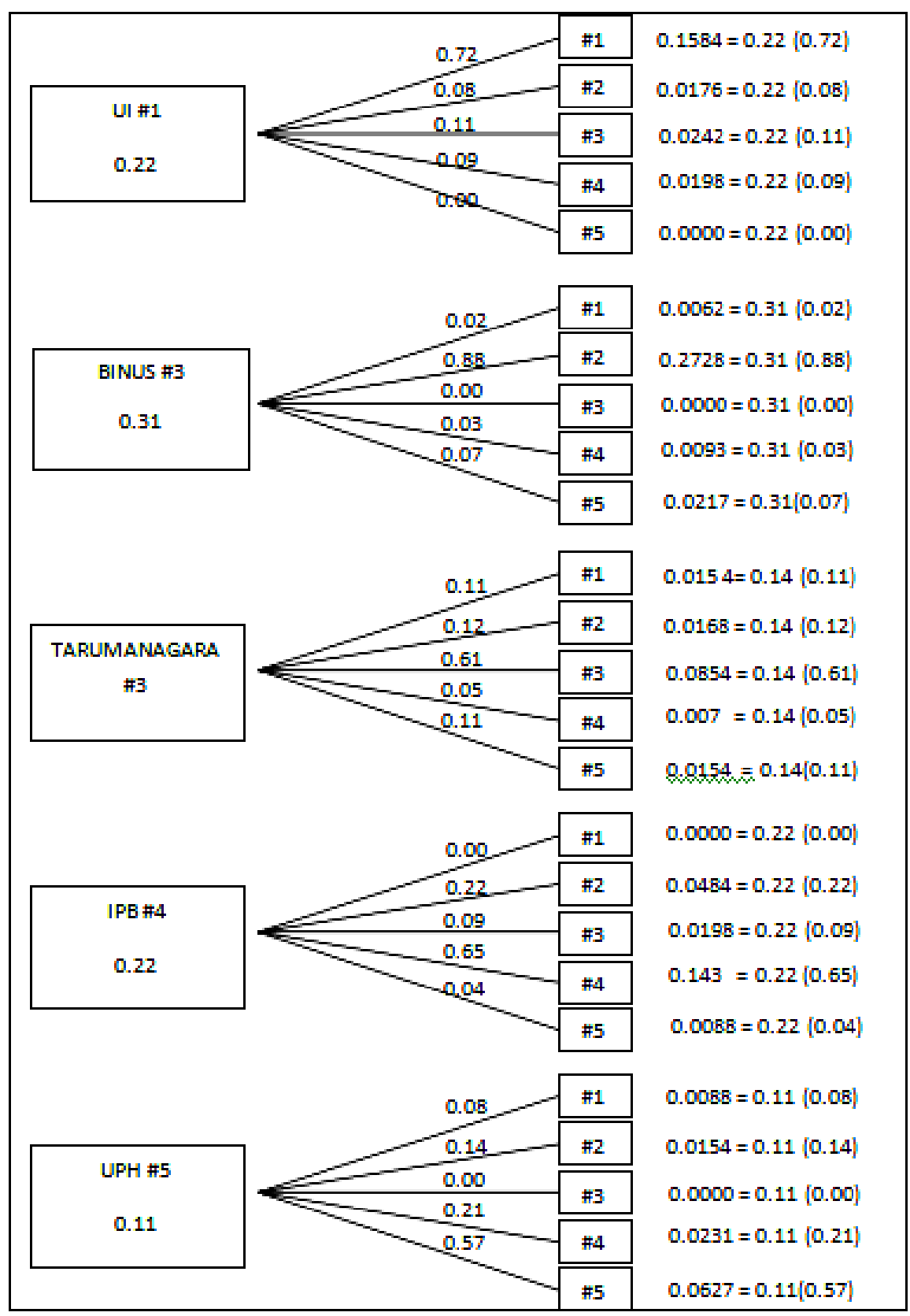

(Sumber: Hasil Pengolahan Data, 2009)

Gambar 8 Diagram Pohon Universitas Swasta

\section{Perhitungan Manual: Pendugaan Peminatan Periode Berikutnya}

Berdasarkan pada data yang telah dikumpulkan, maka pendugaan peminatan untuk kelima universitas swasta untuk periode berikutnya dapat dihitung seperti berikut ini. 


$$
\pi(1)=\pi(0) P
$$

Peminatan Matriks transisi probabilitas

Dugaan Peminatan

Universitas periode berikutnya

$=(\mathbf{0 . 2 2}, \mathbf{0 . 3 1}, \mathbf{0 . 1 4}, \mathbf{0 . 2 2}, \mathbf{0 . 1 1})=\left(\begin{array}{ccccc}0,72 & 0,08 & 0,11 & 0,09 & 0,00 \\ 0,02 & 0,88 & 0,00 & 0,03 & 0,07 \\ 0,11 & 0,12 & 0,61 & 0,05 & 0,11 \\ 0,00 & 0,22 & 0,09 & 0,65 & 0,04 \\ 0.08 & 0,14 & 0,00 & 0,21 & 0,57\end{array}\right)=\begin{aligned} & \mathbf{0 . 1 8 8 8}, \mathbf{0 . 3 7 1}, \mathbf{0 . 1 2 9 4}, \mathbf{0 . 2 0 2 2}, \\ & \mathbf{0 . 1 0 8 6})\end{aligned}$

\section{Pendugaan Titik Ekuilibrium}

Analisis Markov tidak hanya dapat memprediksi pangsa pasar atau peminatan bagi kelima universitas tersebut untuk periode berikutnya, melainkan dapat juga untuk memprediksi peminatan pelajar kelas XII pada titik ekuilibrium, maka didapat titik ekuilibrium peminatan dari 5 universitas tersebut adalah Universitas Indonesia $=0.15(15 \%)$, Universitas Bina Nusantara $=0.562(56.2 \%)$, Universitas Tarumanagara $=0.076(7.6 \%)$, Institut Pertanian Bogor $=0.151(15.1 \%)$, dan Universitas Pelita Harapan $=0.09(9 \%)$.

\section{Perhitungan dengan $Q M$}

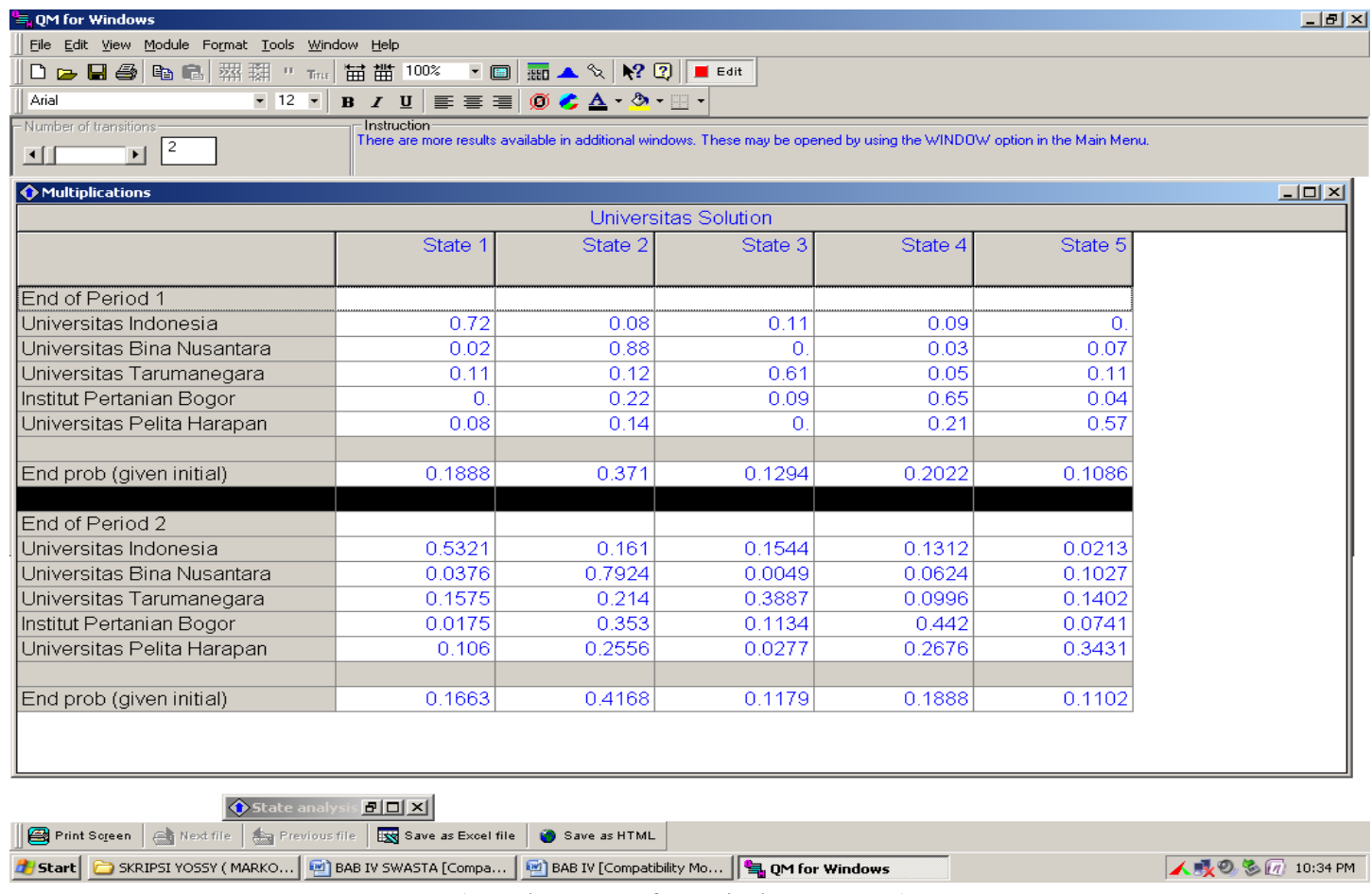

(Sumber: QM for Windows, 2009)

Gambar 9 Tampilan Layar Multications 


\section{SIMPULAN}

Setelah melakukan penelitian dan analisis dari 2 SMA Swasta di Bogor (BPK Penabur dan Budi Mulia), maka dapat ditarik simpulan sebagai berikut. Terdapat 5 universitas favorit, yaitu UI, Universitas Bina Nusantara, Untar, IPB, dan UPH. Prediksi peminatan pada periode berikutnya adalah peminat Universitas Indonesia adalah 0.1888, peminat Universitas Bina Nusantara adalah 0.371, peminat Universitas Tarumanegara adalah 0.1294, peminat Institut Pertanian Bogor adalah 0.2022, dan peminat Universitas Pelita Harapan adalah 0.1086. Berdasarkan hasil analisis, pangsa pasar terbesar dimiliki oleh peminat Institut Pertanian Bogor, yaitu sebesar 20.22\%, sedangkan pangsa pasar terkecil dimiliki oleh peminat Universitas Pelita Harapan, yaitu sebesar 10.86\%. Prediksi peminatan pada kondisi ekuilibrium adalah peminat Universitas Indonesia adalah 0.15, peminat Universitas Bina Nusantara adalah 0.562, peminat Universitas Tarumanegara adalah 0.076, peminat Institut Pertanian Bogor adalah 0.151, dan peminat Universitas Pelita Harapan adalah 0.09. Berdasarkan hasil analisis, pangsa pasar terbesar dimiliki oleh peminat Universitas Bina Nusantara, yaitu sebesar $56.2 \%$, sedangkan pangsa pasar terkecil dimiliki oleh peminat Universitas Tarumanegara, yaitu sebesar 7.6 \%. Sumber referensi pemilihan universitas, yaitu $29 \%$ responden memperoleh referensi dari event promosi yang diadakan universitas tersebut, $25 \%$ responden memperoleh referensi dari iklan, $24 \%$ responden memperoleh referensi dari keluarga, dan $22 \%$ responden memperoleh referensi dari teman. Berdasarkan hasil analisis, sumber referensi terbesar bagi responden dalam memilih universitas yang diminati yaitu berasal dari event promosi $(30,81 \%)$ yang diadakan universitas swasta tersebut.

Saran yang diberikan dalam penelitian ini adalah sebagai berikut. Setelah melakukan analisis, peneliti memberikan saran dan masukan agar hasil analisis dapat dimanfaatkan. Adapun saran-saran yang diberikan adalah sebagai berikut (1) Para universitas dapat lebih meningkatkan media pemasaran yang dilakukan, seperti melalui event promosi, dan iklan untuk dapat menarik konsumen yang lebih besar agar pangsa pasar atau peminat yang dimiliki juga semakin besar. Karena sumber referensi pelajar dalam memilih universitas yang mereka minati sebagian besar berasal dari event promosi dan iklan pada universitas; (2) Para universitas dapat lebih melakukan perbaikan dan peningkatan dalam hal fasilitas perkuliahan, variasi program studi, sarana lainnya, lokasi mudah dijangkau, lokasi dekat tempat tinggal, promosi yang menarik, motivasi promosi, biaya kuliah terjangkau, biaya kuliah murah, status dan akreditas diakui, dosen berkualitas, program pendidikan berkualitas, dan brand image. Perbaikan yang dilakukan tersebut akan meningkatkan kepuasan konsumen. Konsumen yang merasa puas akan memberikan referensi kepada orang lain sehingga pangsa pasar universitas dapat bertambah; (3) Mengingat sumber referensi yang paling tinggi dalam pemilihan universitas tersebut adalah berasal event promosi, disarankan kepada para universitas untuk meningkatkan event-event promosi terutama yang diadakan di sekolah-sekolah seperti bazaar pendidikan, education festival dan lainnya; (4) Penelitian ini kurang fokus pada jurusan atau fakultas yang akan dipilih oleh responden, sebagai contohnya adalah Universitas Bina Nusantara yang terkenal dengan IT nya, maka responden yang memilih Binus pasti dikarenakan IT nya, bagaimana dengan Fakultas FEB, dan apakah responden juga memilih karena peminatan yang ditawarkan? bisa menjadi penelitian selanjutnya. 


\section{DAFTAR PUSTAKA}

Cannon, J.P., et al. (2008). Pemasaran dasar (basic marketing), Jakarta: Salemba Empat.

Djan, I., dan Ruvendi, R. (2006). Prediksi perpindahan penggunaan merek handphone di kalangan mahasiswa (studi kasus pada mahasiswa STIE Binaniaga), Jurnal Ilmiah Binaniaga, 02(1).

Indriantoro, N., dan Supomo, B. (2002). Metodologi penelitian untuk akuntansi dan manajemen, edisi pertama, Yogyakarta: BPFE.

Kotler, P, et al. (2003). Marketing management an Asian perspective, $3^{\text {rd }}$ ed., Singapore: Prentice Hall.

Nugroho, B.A. (2005). Strategi jitu memilih metode statistik penelitian dengan SPSS, Yogyakarta: Penerbit Andi.

Render, B, et al. (2003). Quantitative analysis for management, $8^{\text {th }}$ ed., New Jersey: Prentice Hall International, Inc.

Render, B, et al. (2006). Quantitative analysis for management, $9^{\text {th }}$ ed., New Jersey: Prentice Hall International, Inc.

Santoso, S. (2005). Seri solusi bisnis berbasis ti menggunakan SPSS untuk statistik parametrik, Jakarta: Gramedia.

Siagian, P. (1987). Penelitian operasional (teori dan praktek), Jakarta: Universitas Indonesia.

Siswanto. (2007). Operations research, jilid kedua, Jakarta: Erlangga.

Sudirga, R.S. (2006). Pengaruh biaya promosi, jumlah SPG, dan pelaksanaan promosi yang melibatkan SPG terhadap penjualan dan strategi pemasaran bumbu IF, Telaah Manajemen, $1(2)$.

Taylor, B.W. (2001). Sains manajemen, buku kedua, Jakarta: Salemba Empat.

Umar, H. (2003). Riset pemasaran dan perilaku konsumen, Jakarta: Gramedia. 